\title{
The food intake and energy expenditure of elderly women living alone
}

\author{
By J. V. G. A. DURNIN, ELAINE C. BLAKE AND J. M. BROCKWAY \\ Institute of Physiology, University of Glasgow \\ AND E. ANNE DRURY \\ Ministry of Agriculture, Fisheries and Food, London \\ (Received 2 February 1961一Revised 29 May 1961)
}

The increasing population of elderly people in many countries makes it more necessary than ever to have information on their nutritional requirements. At present few data are available on the nutrition of the elderly, a fact on which several national and international organizations have commented (Durnin, 1960). The elderly, together with the adolescent, are groups particularly vulnerable when food is in short supply. Even when there is no widespread shortage, elderly men and women living alone are more likely to suffer from nutrient deficiencies than the general population since they may often find cooking too much trouble and they may have insufficient money to buy enough of the correct food.

We have previously investigated the food intake and energy expenditure of young and of middle-aged women (Durnin, Blake \& Brockway, 1957) and were interested in obtaining comparable information for elderly women, especially since conflicting results have been reported by other investigators. For instance, Pyke, Holmes, Harrison \& Chamberlain (1947) found that the mean calorie intake of women aged about 60 was $1500 \mathrm{kcal} /$ day. Baines \& Hollingsworth (1955) described National Food Survey estimates which apparently show the calorie value of the foods purchased by women in Britain, aged between 60 and 69 and living alone, to be about $2900 \mathrm{kcal} /$ day. On the other hand, Bransby \& Osborne (1953), in an investigation of women in the same age range and who were either living alone or with their husbands, estimated their calorie intakes at $1800-1900 \mathrm{kcal} /$ day. However, the few and occasionally divergent experimental data on the food intake of elderly women are in contrast to the surprising uniformity of the recommendations of calorie requirements proposed by various official bodies. For example, the (U.S.A.) National Research Council: Food and Nutrition Board (1958) recommended that for women aged 65 and weighing about $130 \mathrm{lb}$ an intake of $1850 \mathrm{kcal} / \mathrm{day}$ is desirable. The FAO: Committee on Calorie Requirements (1957) advised an intake of $1920 \mathrm{kcal} /$ day.

A study of the food intake and, as a check on calorie requirements, of the total energy expenditure of a group of elderly women living alone was undertaken in the Glasgow area. The subjects also kept records of their food purchases, by a budgetary method similar to that used for the National Food Survey in Britain before 195I, the results of which will be published by Durnin \& Blake in another paper. 


\section{METHODS}

General. Seventeen women took part in the survey. They all lived in Paisley, a large town about 7 miles from Glasgow. Ten were studied during March and the other seven in November 1958.

The mean age of the seventeen women was 66 years (S.D. $\pm 2 \cdot 6$ ), their mean height

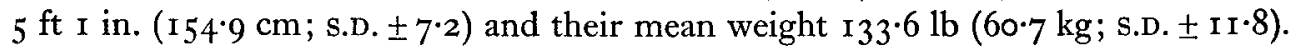

Their living conditions varied considerably. Three women lived in one-room flats, one of which had a separate small kitchen; the toilet was a communal one and was outside the flats. Eleven lived in two-room flats, three of which contained separate kitchens and bathrooms and four others had separate inside toilets; the remaining four used a communal toilet. Three other subjects lived in three-room flats, each with a separate kitchen and bathroom. With four exceptions, all the flats were well-kept, comfortable and easy to run. Three subjects had part-time jobs as cleaners and, apart from three who were crippled with arthritis, all the others were active and some led very full social lives. Pathological conditions, detectable by questioning, were limited to the arthritic women, to one woman who was a mild diabetic and another who had retired from nursing because of 'myocarditis' and who, being overweight, was on a reducing diet. All the subjects were in the 'working' or so-called lower or lower-middle class.

Selection of subjects. A random sample of women aged 6o-69 was drawn by blocks from the registers of patients kept at the local Executive Council Offices in Paisley of the National Health Service. The list of names taken by this means was then checked against the electoral roll in a preliminary attempt to eliminate women who did not appear to be living alone. In the March survey a letter was then sent to the family doctors of the subjects so selected. A short explanation was included of the purpose of the study and they were asked to get in touch with the particular patient and establish whether she might be willing to take part in such an investigation. A letter was simultaneously sent out to each of the subjects describing the general reasons for the study. The family doctors subsequently returned the names of those of their patients who were provisionally willing to co-operate and these women were visited by two of us who explained exactly what the survey would involve and, if they then consented, arrangements were made to begin the experiment. Thirty-four names in all were sent out to the family doctors and of these women thirteen were unsuitable, either because they were not in fact living alone or else because they intended to spend a large part of the week away from home. Eleven were unwilling to participate, so that ten, almost $50 \%$, co-operated. In the November survey the subjects were approached directly without the intervention of the family doctors, who might possibly have caused a statistical bias by influencing the subject in her decision. In the second part of the study letters were sent to thirty-eight subjects chosen in the same way as for the first part and they were visited a day or two later. When those who were not living alone (three) or were seldom in (seven) or were seriously ill (four) were eliminated, the positive response was again about $50 \%$-i.e. thirteen out of twenty-four (the results for six of the thirteen are not described here since they did only a survey 
of the National Food Survey type). One woman discontinued the study at the end of the Ist day because it was too troublesome.

Measurement of energy expenditure. Each subject kept a minute-by-minute record of her various activities during the week of the survey. It was entered on special diary cards, similar to those described by Garry, Passmore, Warnock \& Durnin (1955), which were meticulously checked daily by one or other of the authors. The energy expenditure of the individual subjects in the principal activities (sitting, standing, walking and housework) was measured by indirect calorimetry with the Max Planck respirometer (Kofranyi \& Michaelis, I940; Müller \& Franz, 1952). Estimates of the energy expended in other activities were made, based on the subject's weight, knowledge of the manner of her particular activity and of the other measurements of her energy output. The total daily expenditure of energy was then calculated by multiplying the time spent in each activity by its calorie factor and summing the results. The accuracy of this method has been discussed by Durnin \& Brockway (I959).

In order to simplify the introduction to the experiment during the November survey, six out of the seven subjects recorded only food intake for the Ist day, and three of these six continued to record only the food intake for the 2nd day; thus, one of these subjects has a measurement of energy expenditure for 7 consecutive days, three for 6 days and the remaining three for 5 days. In each record the week-end was included. During the March study, two subjects were unable to complete their diary cards adequately and no attempt has been made to estimate their energy output.

Measurement of food intake. Total daily food intake was measured for the individual subjects by the individual-inventory method, described by Garry et al. (1955) and Durnin et al. (1957). The separate foods were weighed on dietetic spring balances, which the subjects were taught to use accurately. Polyvinyl jugs were provided for measuring liquids, and plastic containers were given for easy weighing of foods in frequent use, such as butter, jam or sugar. The weights of foods and of plate wastage were entered in a log-book which was checked during the daily visit of one of the team of dietitians. (This daily visit is necessary, not only to try to avoid errors but also to benefit overanxious subjects who become worried about any uncertainties of procedure.) Those subjects who had meals away from home either took their scales with them or, if it was too inconvenient, entered fairly detailed descriptions of these meals in notebooks. In the latter event, quantities were assessed by a dietitian and written in the log-book.

The nutrient value of the diet was calculated from McCance \& Widdowson's (i960) The Composition of Foods; net calorie values of 4,9 and 3.75 were assigned to protein, fat and carbohydrate respectively.

Both with regard to the estimates of food intake and of energy expenditure, it was continually impressed on the women that any change in their eating habits or in their ordinary daily routine would render the whole study useless, and we are reasonably confident that little alteration took place. 


\section{RESULTS}

There was no significant difference in the results obtained during the studies in March and in November and they have therefore been combined. The mean values, and standard deviations, for the intake and expenditure of calories for the seventeen elderly women are shown in Table I. The agreement between the group values for intake and expenditure was satisfactory (the difference was less than $5 \%$ ), although there was a considerable variability within the individuals. This finding seems to be common to all such studies (Durnin, 196r). Occasionally some explanation can be

Table I. Mean values with standard deviations and ranges of daily energy intake and expenditure of seventeen elderly women

(The results are quoted as calculated, i.e. to the nearest unit, although we are well aware that the accuracy, even of this comparatively accurate method, is such that it would be more reasonable to round off values to the nearest hundred)

$\begin{array}{lccc} & \text { Mean } & \begin{array}{c}\text { Standard } \\ \text { deviation }\end{array} & \text { Range } \\ \text { Intake (kcal/day) } & \mathbf{1 8 9 4} & 299 & \text { I ro7-2283 } \\ \text { Expenditure (kcal/day) } & \mathbf{1 9 8 7} & 248 & \mathbf{1 4 9 2 - 2 4 0 9}\end{array}$

Percentage difference between mean intake and expenditure $=4.7$

Table 2. Mean values and ranges of time spent daily and equivalent energy expenditure on various activities by seventeen elderly women

\begin{tabular}{|c|c|c|c|c|}
\hline \multirow[b]{2}{*}{ Activity } & \multicolumn{2}{|c|}{ Time (min) } & \multicolumn{2}{|c|}{ Energy (kcal) } \\
\hline & Value & Range & Value & Range \\
\hline Lying in bed & $5^{81}$ & $494-689$ & 485 & $406-66 I$ \\
\hline Personal necessities & 29 & $5-47$ & 85 & $12-160$ \\
\hline $\begin{array}{l}\text { Standing activities (includes } \\
\text { housework) }\end{array}$ & 305 & $134-400$ & $62 I$ & $364-848$ \\
\hline Sitting & 436 & $260-486$ & 529 & $312-773$ \\
\hline Walking & 66 & $19-149$ & 205 & $67-477$ \\
\hline Shopping & 23 & $4-48$ & 62 & $40-113$ \\
\hline Total & 1440 & & 1987 & \\
\hline
\end{tabular}

suggested for a large individual difference between intake and expenditure of calories; e.g. one woman with $20 \%$ excess of expenditure over intake was on a weight-reducing dietary regimen because of 'myocarditis' complicated by obesity. Another, whose intake was $13 \%$ less than her expenditure of energy, was suffering from loss of appetite because of emotional upset - the survey happened to coincide with the anniversary of her husband's death.

The mean time spent on the varying activities by the subjects together with the appropriate mean energy output are shown in 'Table 2. 'Personal necessities' includes washing oneself, dressing, using the toilet, and 'standing activities' includes housework, all of the various forms of which have been combined in the presentation of Table 2. Some of the miscellaneous activities included remedial exercises for one of the arthritic women, and dancing, playing cards and playing the piano for one of the more socially inclined subjects. Several of them visited their families, one undertook 
some social work such as door-to-door collections, another cleaned her brother's house weekly, and most of them entertained their friends or were entertained by them. The average length of time spent in bed was almost to h a night-possibly one of the compensations of being retired and living alone. On the other hand, more than $\mathrm{I} h$ was spent daily in walking outdoors, which compares favourably with this activity in some population groups.

Table 3. Contribution of protein, fat and carbohydrate to the mean daily energy value of the diets of seventeen elderly women

\begin{tabular}{|c|c|c|c|c|}
\hline \multirow[b]{2}{*}{ Nutrient } & \multicolumn{2}{|c|}{$\mathrm{kcal} /$ head } & \multicolumn{2}{|c|}{ As a percentage of total } \\
\hline & Value & Range & Value & Range \\
\hline Protein & 250 & I $17-340$ & 13.2 & $10 \cdot 0-16.7$ \\
\hline & 771 & $454-947$ & $40 \cdot 7$ & $36 \cdot 3-47 \cdot 2$ \\
\hline Carbohydrate & 873 & $536-1174$ & $46 \cdot I$ & $38 \cdot 6-53 \cdot 7$ \\
\hline Tot & 1894 & & $100 \cdot 0$ & \\
\hline
\end{tabular}

Table 4. Mean daily intake of some nutrients (with ranges and some standard deviations) of seventeen elderly women

\begin{tabular}{|c|c|c|c|}
\hline Nutrient & Value & $\begin{array}{l}\text { Standard } \\
\text { deviation }\end{array}$ & Range \\
\hline Protein (g) & $62 \cdot 4$ & $12 \cdot 0$ & $29 \cdot 2-85 \cdot 0$ \\
\hline Fat $(g)$ & $85 \cdot 7$ & $14 \cdot 6$ & $50 \cdot 4-105 \cdot 2$ \\
\hline Carbohydrate (g) & $232 \cdot 1$ & $43 \cdot 7$ & $143^{\circ} 0-313^{\circ} 1$ \\
\hline Calcium (mg) & 845 & 214 & $556-1435$ \\
\hline Iron (mg) & 10.7 & $2 \cdot 8$ & $3 \cdot 1-15 \cdot 7$ \\
\hline Vitamin A (i.u.) & 3563 & 1033 & I $759-5005$ \\
\hline Thiamine (mg) & 0.86 & 0.26 & $0.39-\mathrm{I} \cdot 08$ \\
\hline Riboflavin (mg) & $I \cdot I$ & 0.18 & $0.7 I-I \cdot 44$ \\
\hline Nicotinic acid (mg) & $9 \cdot 2$ & - & $4 \cdot 2-23 \cdot 4$ \\
\hline Ascorbic acid (mg) & $3 I$ & - & $6-94$ \\
\hline Vitamin D (i.u.) & 71 & 一 & $22-173$ \\
\hline
\end{tabular}

The percentage of calories derived from protein, fat and carbohydrate, together with the calorific equivalents, are given in Table 3. Protein accounts for a perhaps surprisingly large percentage, 13.2. A little less than $40 \%$ of this total was derived from vegetable protein. In Table 4 are shown the amounts of protein, fat, carbohydrate, calcium, iron and some of the vitamins consumed daily by the women. Although there was a large individual scatter, most of the intakes fell within, or near, nationally recognized allowances.

Of the $40 \%$ contribution of fat to the total calorie intake, butter provided more than a quarter, representing $\mathrm{II} \cdot 2 \%$ of the total calories consumed; another quarter was derived from milk, eggs and cheese, and just over $20 \%$ of the fat came from cakes or biscuits; meat and meat products supplied about $15 \%$. Margarine, on the other hand, accounted for only $\mathrm{i} \%$ of the total calories; only one of the subjects took margarine in preference to butter for spreading on bread. Bread, buns, biscuits, cakes and cereal products were responsible for almost $800 \mathrm{kcal} /$ day, i.e. about $40 \%$ of the total intake; 
within this quantity, cakes, biscuits and scones provided about one-third more calories than did bread and rolls.

Of the daily calcium intake, about $340 \mathrm{mg}$ were from milk, of which the average intake was about $\frac{1}{2} \mathrm{pint} / \mathrm{head}$ daily. Another roo $\mathrm{mg}$ were obtained from cheese, and bread, rolls, scones, cakes and biscuits contributed about $200 \mathrm{mg}$.

The mean intake and range for the various vitamins given in Table 4 show that, although some of the individual results were low, the mean values approximated to most recommended allowances.

The eating pattern of the women did not always coincide with preconceived ideas about eating habits applicable to Scottish elderly women. For example, breakfast cereals were very popular but only three of the women took porridge. As mentioned before, only one subject used margarine on her bread, all the rest taking butter. Only seven of the subjects ate milk puddings and only three took other puddings regularly. Buns, biscuits and cakes were eaten by all the women with one exception, the diabetic. The mean consumption of eggs was four/week and they were usually boiled. Fresh milk was used regularly by all except one of the subjects who preferred condensed milk. Nine women had some cheese, but it accounted for only about $80 \mathrm{kcal} / \mathrm{head}$ daily. Three women had no fruit during the period of survey and only six took green vegetables regularly. Two of the women never ate fish, but it was a popular dish with the remainder; it was mainly white fish, and was prepared steamed or fried with equal frequency. Soups were popular and were almost always home-made. Beef was the meat most commonly eaten, although some pork, mainly bacon or cooked ham, and some stewed mutton or mutton chops were also consumed. Sausages and canned meats were taken occasionally by most subjects although meat pies were not popular. Only two of the subjects ate poultry. Chocolate was more popular than boiled sweets, but only three of the subjects consumed more than 4 oz during the whole of the week. A negligible amount of cream and ice-cream was eaten.

\section{DISCUSSION}

The results obtained for the seventeen elderly women seem to suggest a value for their calorie requirements of about $1900 \mathrm{kcal} / \mathrm{day}$. This agrees remarkably with the official recommendations, although it is closer to the FAO: Committee on Calorie Requirements (1957) value of $1920 \mathrm{kcal} /$ day than to the $185^{\circ} \mathrm{kcal} /$ day proposed by the (U.S.A.) National Research Council: Food and Nutrition Board (1958). However, such differences in practice, and particularly with a comparatively small group such as this, are meaningless. Our findings are similar to those of Bransby \& Osborne (1953), already mentioned, and to those of Gillum \& Morgan (1955) who investigated ro6 women, aged 6o-69 and weighing around $65 \mathrm{~kg}$, and assessed the calorific value of their diets as $1800 \mathrm{kcal} /$ day. Our values are much lower than the results reported in the National Food Survey (Baines \& Hollingsworth, 1955) for this population group in Britain, even when the usual allowances are made for wastage, and are significantly higher than the values of Pyke et al. (1947) and of Mertz, Baxter, Jackson, Roderuck \& Weis (1952). The last two teams of investigators reported mean food intakes of women 
of similar age to ours to be about $1400-1500 \mathrm{kcal} /$ day. However, our present findings agree with another series of measurements on housewives of about the same age but living in households of various family sizes (Durnin, Blake, Allan, Shaw \& Blair, I96r); the fact that the subjects were living alone would therefore appear to have no undue influence on the results. Some of the elderly women were spinsters and some were widows, but no difference was apparent in the energy values determined or in their body-weight; any emotional effects attributable to marital status were not reflected by different nutritional states, at least in this small group.

Table 3 shows that almost $4 \mathrm{I} \%$ of the total calorie intake was derived from fat. This seems a relatively high proportion, but lack of data for comparison makes it difficult to be certain. It is almost exactly the same as the values for young and for middle-aged women found by Durnin et al. (1957), but is considerably higher than the $34-35 \%$ reported for men working in heavy industry (Garry et al. 1955).

\section{SUMMARY}

I. The food intake and total energy expenditure of seventeen elderly women were measured during a period of $\mathrm{I}$ week. The women were aged between 60 and 69 years and all lived alone.

2. The mean intake and the mean expenditure of energy were about $1900 \mathrm{kcal} / \mathrm{day}$; there was a good agreement between the two estimates.

3. The calories derived from protein, fat and carbohydrate accounted for about ${ }_{13}, 4 \mathrm{I}$ and $46 \%$ respectively of the total calorie intake.

4. Values for the intakes of calcium, iron and some of the vitamins are also given.

5. The energy requirement assessed by these measurements of food intake and of energy expenditure seems to agree remarkably well with most of the appropriate official recommended allowances.

This work was carried out during the tenure (by J. D. and J. B.) of a research grant from the Scottish Hospital Endowments Research Trust. It was partly financed by the Department of Health for Scotland and partly by the Medical Research Council.

We are grateful to Miss Dorothy Hollingsworth, O.B.E., of the Ministry of Agriculture, Fisheries and Food, and to Dr W. T. C. Berry of the Ministry of Health, who instigated part of the study. We are also indebted to Dr R. A. Robb of the Department of Statistics, University of Glasgow, for statistical assistance, to the officials of the National Health Service Local Executive Council in Paisley for assistance in selecting the subjects and to Sir Kenneth Cowan, Department of Health for Scotland, for advice.

\section{REFERENCES}

Baines, A. H. J. \& Hollingsworth, D. F. (1955). Proc. Nutr. Soc. 14, 77.

Bransby, E. R. \& Osborne, B. (1953). Brit. F. Nutr. 7, 160.

Durnin, J. V. G. A. (1960). Proc. Nutr. Soc. 19, 140.

Durnin, J. V. G. A. (196r). \%. Physiol. r56, 294.

Durnin, J. V. G. A., Blake, E. C., Allan, M. K., Shaw, E. J. \& Blair, S. (196r). F. Nutr. (In the Press.)

Durnin, J. V. G. A., Blake, E. C. \& Brockway, J. M. (1957). Brit. F. Nutr. II, 85.

Durnin, J. V. G. A. \& Brockway, J. M. (1959). Brit. F. Nutr. 13, 41. 
FAO: Committee on Calorie Requirements (1957). F.A.O. nutr. Stud. no. I5.

Garry, R. C., Passmore, R., Warnock, G. M. \& Durnin, J. V. G. A. (1955). Spec. Rep. Ser. med. Res. Coun., Lond., no. 289.

Gillum, H. L. \& Morgan, A. F. (1955). $\mathscr{~}$. Nutr. 55, 265.

Kofranyi, E. \& Michaelis, H. F. (1940). Arbeitsphysiologie, I1, 148.

McCance, R. A. \& Widdowson, E. M. (1960). Spec. Rep. Ser. med. Res. Coun., Lond., no. 297.

Mertz, E. T., Baxter, E. J., Jackson, L. E., Roderuck, C. E. \& Weis, A. (1952). F. Nutr. 46, 3 I3.

Müller, E. A. \& Franz, H. (1952). Arbeitsphysiologie, r4, 166.

National Research Council: Food and Nutrition Board (1958). Publ. nat. Res. Coun., Wash., no. 589, revised.

Pyke, M., Holmes, S., Harrison, R. \& Chamberlain, K. (1947). Lancet, 253, $46 \mathrm{I}$. 